\title{
On homology Between Ming Style Furniture and Ancient Chinese Architecture
}

\author{
Wang Wentian, ${ }^{1,}$, Sun Ming ${ }^{2, b^{*}}$ \\ ${ }^{1}$ School of art and design, Tianjin University of Science and Technology, Binhai New Area, Tianjin, Tianjin, China. \\ ${ }^{2}$ School of art and design, Tianjin University of Science and Technology, Binhai New Area, Tianjin, Tianjin, China. \\ aHellotiange@163.com \\ b*A1b2sun@163.com
}

\begin{abstract}
Furniture is an important part of the interior space of architecture. In terms of its form, furniture is the extension and extension of the inside and outside space of the building in the form of art. From its function, furniture has realized the user's demand for function in the building space, and at the same time, as an important configuration of interior furnishings, The shape of furniture is directly related to the overall coordination of architectural style. In this paper, as the refinement of Ming style furniture culture, the homology of Ming style furniture and ancient Chinese architecture is demonstrated by four examples of structural form, modeling law, material convergence and accessory components, providing reference and help for the study of Ming style furniture culture.
\end{abstract}

Keywords: Ming style furniture, ancient architecture, construction, woodwork, homology

\section{浅议明式家具与中国古代建筑的同源性}

\author{
王文恬 $1, a$ ，孙明 $2, b^{*}$
}

1 天津科技大学艺术设计学院, 滨海新区, 天津, 天津, 中国

2 天津科技大学艺术设计学院, 滨海新区, 天津, 天津, 中国

${ }^{a}$ Hellotiange@163.com

b*A1b2sun@163.com

\section{摘要}

家具作为建筑内部空间的重要组成部分，从其形式上看，家具就是建筑内外空间在造型艺术上的扩展与延伸; 从其功能上看, 家具实现了使用者在建筑空间中对功能的诉求; 与此同时, 作为室内陈设的重要配置, 家具的 形制也直接关乎建筑风格整体是否协调统一。本文作为明式家具文化研究的细化，以结构形制、造型规律、材 料衔接、附属构件四个方面的实例图式来展示明式家具与中国古代建筑的同源性，为明式家具文化研究提供参 考与帮助。

关键词: 明式家具；古代建筑；营造；木作；同源性

\section{1. 前言}

作为在世界建筑史上最先采用框架结构的中国 古代建筑, 其选材与西方古代建筑天差地别, 西方古 代建筑多选用石材, 而中国古代建筑却独爱木材。我 国古代称建筑行业为“营造”, 而“营造”又有大木作与 小木作之分, 其中小木作就是指家具的制作。由此可
见, 我国古代建筑营建与家具建造如出一辙。因此, 大木作选用的材料在小木作的家具制作工艺当中变 得游刃有余, 同时也直接影响到了中式传统家具的演 变与发展。与西方家具史大相径庭的是, 中式传统家 具在长时间的发展过程当中形成了工艺精深、重构造、 轻装饰的特质，这类与建筑空间浑然一体的中式家具 系统在世界家具史上也别开生面。[1]明式家具发展至 清代, 其种类繁多且功能明确, 这一因素很大程度上 
促使了更多的明式家具依照我国古代建筑的室内空 间尺寸来量身定做，因此与我国古代建筑风格相匹配 的家具陈设也就散发出对称、稳定与均衡的气势。并 风俗习惯与地区文化的特性，形成了独特的家具气概。 例如京式家具、苏式家具、广式家具等。

\section{2. 基于结构形制下明式家具与古代建筑的同 源性}

在我国古代，家具陈列与建筑的关系密不可分。 随着经济带动手工业日渐兴盛，建筑营造技术的进步 促使人们席地起居的习惯也随之变化。魏晋南北朝时 出现了高形坐具; 唐代更是出现了高形桌椅和屏风等 新式家具, 西安唐代天宝十五年高元珪墓葬壁画中所 绘制的大型座椅就是很好的例子, 其椅背结构借用建 筑营造中斗拱的作法更能说明我国古代建筑与家具 制作之间密不可分的联系（图 1)。直至北宋年间，由 钜鹿宋城遗址中出土的木制桌椅以及白沙宋墓壁画 《开芳宴》内附有脚踏的椅子, 仍能清晰地看出早期 家具的梁柱式框架结构是受建筑木作的影响（图 2、 3)。因此, 建筑营造中的结构, 也就自然而然地被移 用于家具制作当中。

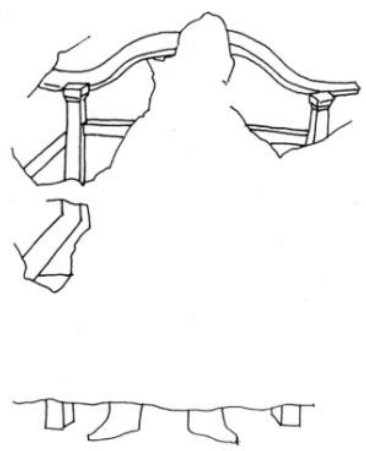

图 1 唐代高元珪墓壁画上的椅子
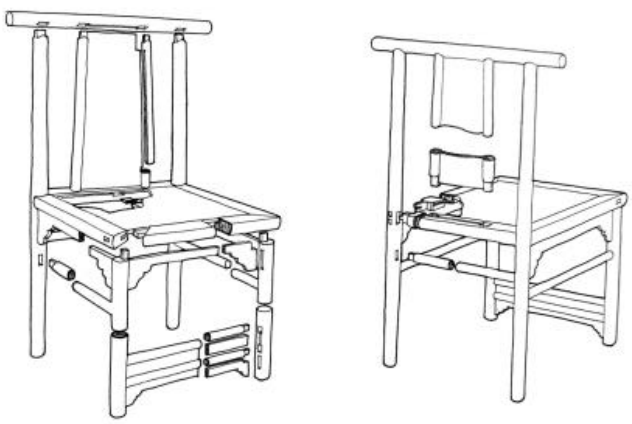

图 2 钜鹿宋椅结构示意图

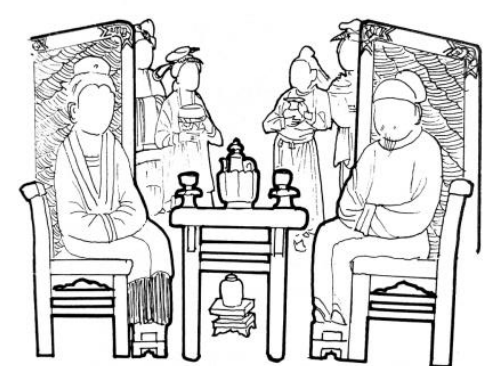

图 3 北宋《开芳宴》壁画

\section{3. 基于造型规律下明式家具与古代建筑的同 源性}

“束腰”与“托腮”就是两个很好的例证，直到今天 仍被许多家具匠人广泛运用。“束腰”是指家具上的一 个收缩部分，一般指在面板下装饰一道缩进面沿的线 条, 形象明显, 故名“束腰”。家具的束腰源于须弥座, 所谓须弥座实际上就是大型的壼门台座。魏晋南北朝 时期, 佛教文化兴盛于中原地区，对当时文化、建筑、 家具领域产生了重大的影响。早期的须弥座有云冈石 窟的北魏浮雕塔基、敦煌唐代石窟中的龛座、五代王 建墓的棺床等等, 它们的结构如出一辙, 中间都有一 个收缩的部分, 由此再向外展开 (图 4-6)。尽管一般 家具上的束腰都比较窄, 但明式家具中就出现了在高 束腰部位安装抽屉的方桌。由于抽屉对高度的需求与 抽庶两旁出现的立柱，其造型结构就更加形同立柱分 隔的须弥座。然而，这个今天仍被我们广泛使用的家 具名词“束腰”与宋代须弥座上的名称完全相同，也不 得不使我们想到二者之间的联系（图 7-10）。“托腮” 所处的位置正与须弥座束腰下的“叠涩”雷同。《营造 法式》一书既然能把“叠涩”写成“挞涩”，那么数百年 间匠人们口口相传, 将“叠澀”称为“托腮”也就不足为 奇。这也就为我们研究古代大小木作的关系提供了一 条有力的线索。

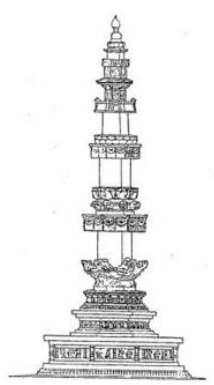

图 4 云冈北魏浮雕塔

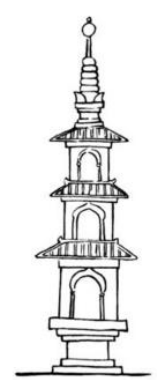

图 5 赵县陀罗尼经幢 


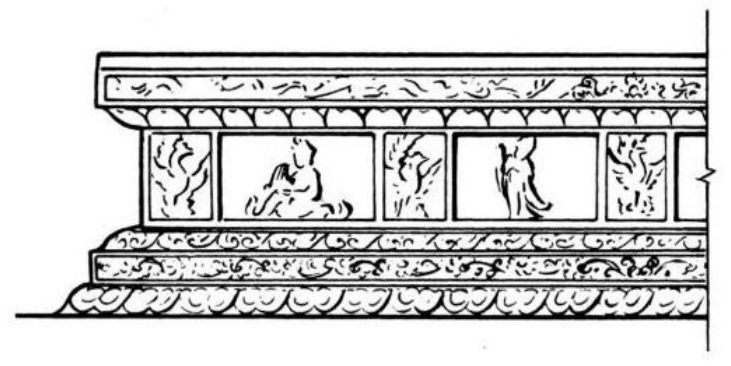

图 6 五代王建墓棺床

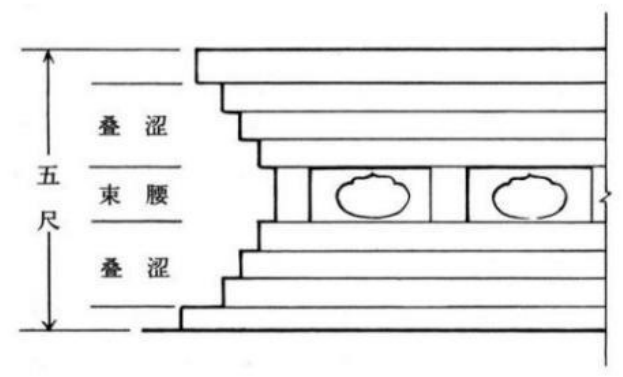

图 7 《营造法式》殿阶基示意图

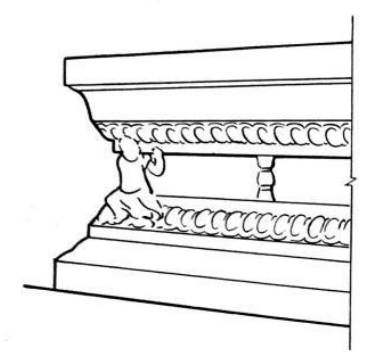

图 8 正定开元寺大殿须弥座

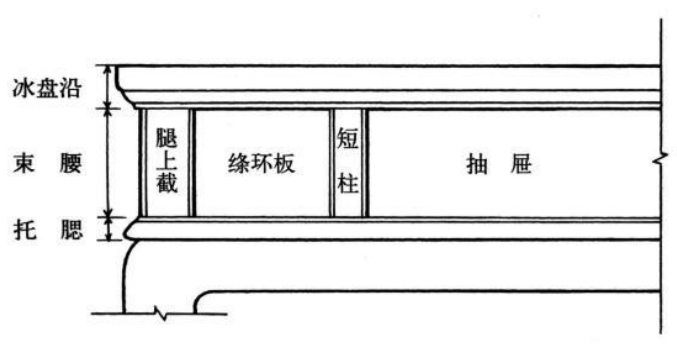

图 9 高束腰带抽屉方桌局部

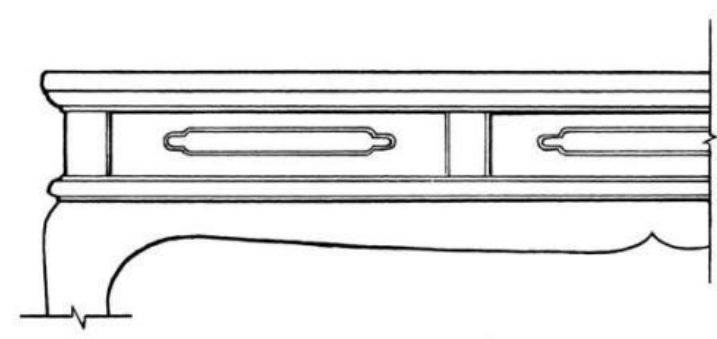

图 10 高束腰条桌局部

\section{4. 基于材料衔接下明式家具与古代建筑的同 源性}

众所周知我国古代建筑的造型之美, 庄严宏伟的 氛围亦是响彻东西方文明的上空。但其独特的构造之 美也是经历了由简陃到成熟复杂再趋而简练的过程, 三千年的发展使中国木架结构体系成为民族的瑰宝。 木架结构中抬梁式与穿斗式两者使用范围较多的是 抬梁式结构, 其多用于宫殿、庙宇、寺院等大型建筑 当中（图 11、12）。例如长陵裕恩殿、孔庙奎文阁、 南禅寺大殿等等 (图 13)。俗语中“墙倒屋不塌”的说 法就很形象地诠释了木架结构的受力特点。明式家具 中大到可以承置储物的联二㴟, 小到起居日用的条案 方登的结构都含有木结构建筑营造的形式, 其稳固性 说明了结构受力合理（图 14）。我国古代建筑以梁、 柱作为重要结构支撑, 与之相应, 明式家具以腿、足 作为支撑做架。这都与我国古代建筑的构造有异曲同 工之处。 ${ }^{[2]}$

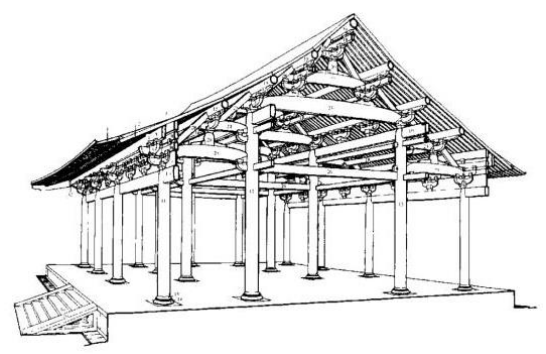

图 11 抬梁式构架示意图

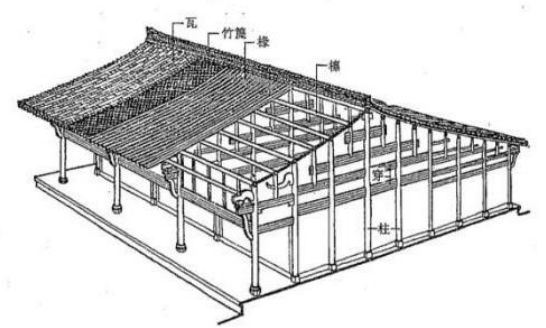

图 12 穿斗式构架示意图 


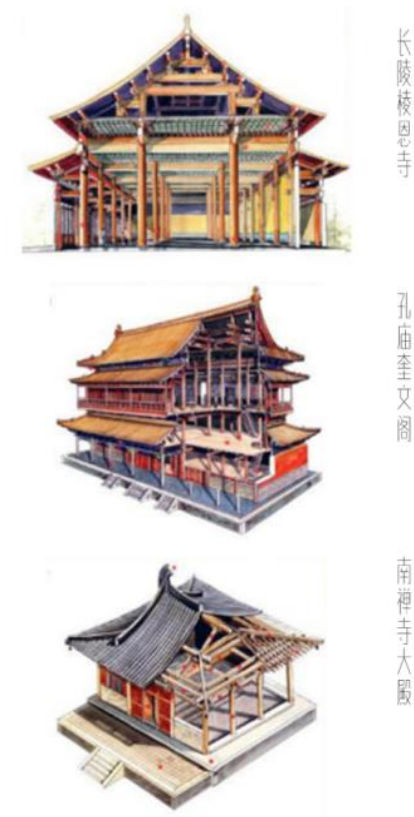

图 13 建筑结构示意图
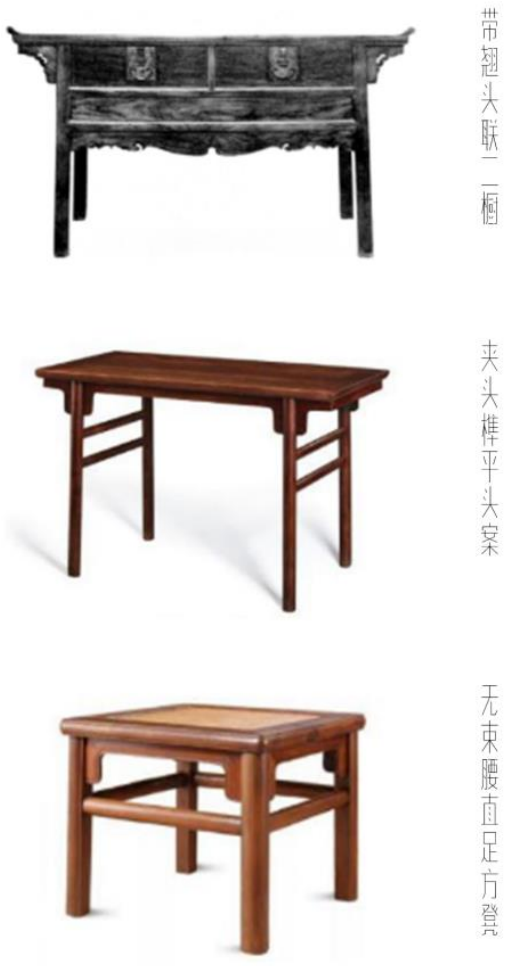

图 14 家具结构示意图
檐柱与额枋间加固承重的功能逐渐演变为单纯的装 饰功能（图 15）。比较明式家具中的牙子, 由最初坚 固家具结构的作用也逐渐趋于镂空的花饰和简洁的 线条, 例如卷云纹、锼风纹、草龙纹、卷叶纹等等 (图 16)。

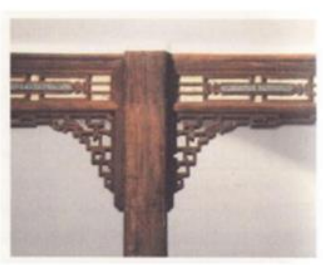

龙门雀

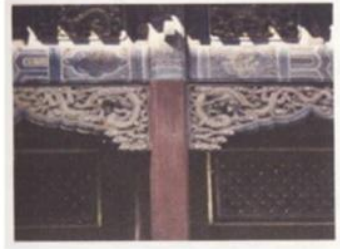

大雀替
图 15 建筑中的雀替造型

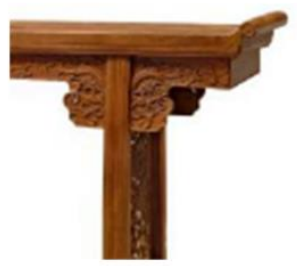

龙㥗

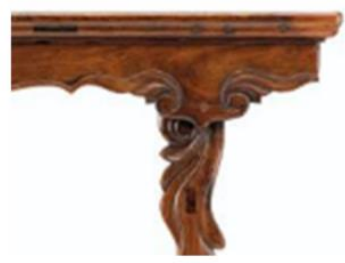

毁风纹
图 16 家具中的牙子造型

再者, 目前所知最早出现的勾栏图像实物, 是西 周晚期青铜器兽足方鼎两侧的十字格棂勾栏 (图 18)。 后期勾栏形象相继出现在墓葬、石窟当中, 例如东汉 密县后士郭 2 号墓出土的明器（图 19、20)、北魏云 冈石窟第 9 窟前室北壁的曲尺勾栏（图 21）、哈尔基 山辽墓彩棺周围的曲尺勾栏 (图 22) 等等。值得对比 的是这件用紫檀制成的三屏风攒接围子罗汉床（图 23), 其曲尺式三面围子又不难让我们联想到寺院中 罗汉像的台座。
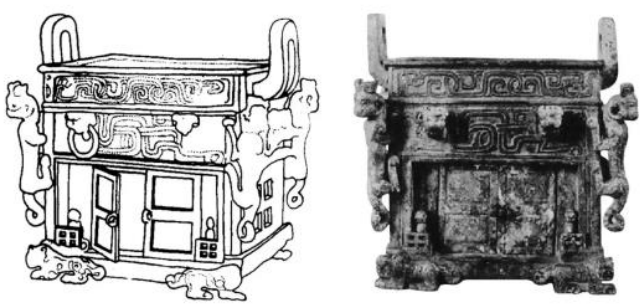

图 17 西周晚期兽足方鼎

\section{5. 基于附属构件下明式家具与古代建筑的同 源性}

在数千年的发展历程中, 我国古代木结构建筑也 不断丰富着自己的外在形态, 大量的部件结构始终随 着材质、气候、信仰、需求的变化而变化。古代建筑 中的雀替、勾栏以及固定构件的铁钉基本没有逃出营 造法式的框架体系。雀替在我国古代建筑中由起初在 


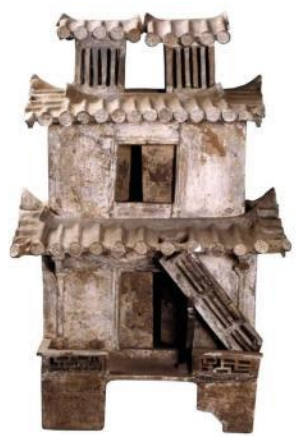

图 18 东汉后士郭 2 号墓

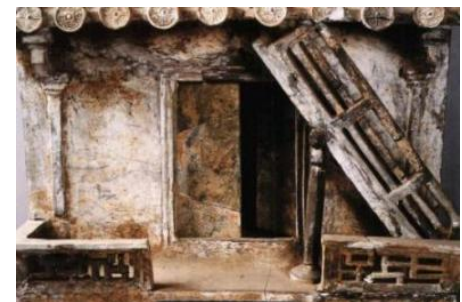

图 19 东汉后士郭 2 号墓放大图

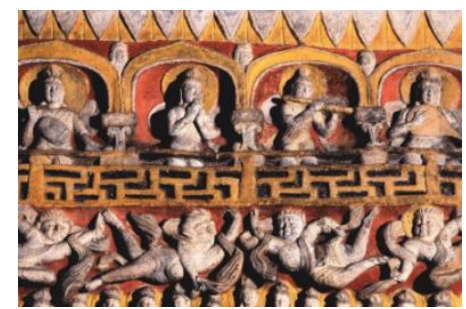

图 20 北魏云冈石窟第 9 窟前室北壁

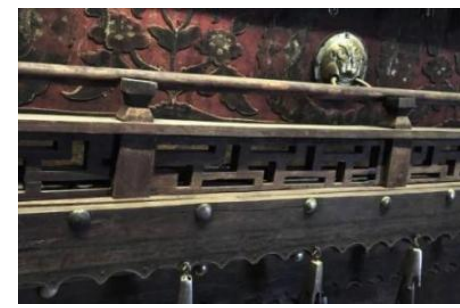

图 21 哈尔基山辽墓彩棺曲尺勾栏放大图

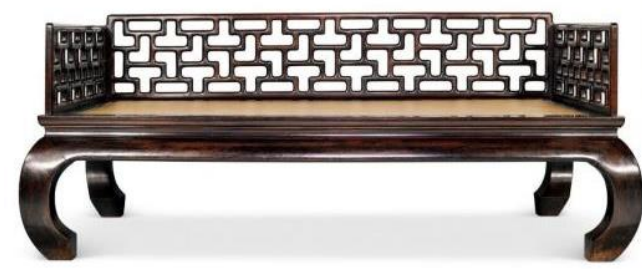

图 22 清早期紫檀三屏风攒接围子罗汉床

钉是古建筑各部分固定构件的统称，其包含的范 围很广，依照所用的位置，形状和尺寸都有所不同。 在战国时期燕下都遗迹中发现了铁制瓦钉，说明至迟 在战国时期建筑上用钉的手段就已出现。[3]木结构建 筑中现存最早的用钉实物是山西五台南禅寺的椽钉。
当然, 古代建筑中的铜铁部件还有门钹、门钉、铺首、 合页、护角等等 (图 24), 但这一切经过家具匠人们 的妙手拈来，最终在明式家具中的呈现称得上是“惜 墨如金”（图 25)。不过，我们也绝不能否认其中仍存 在一些装饰不足, 甚至令人生厌且不堪入目的作品。

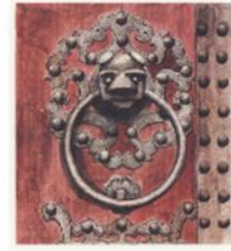

铺菌

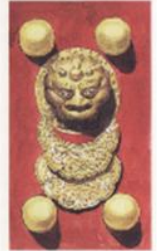

门铺

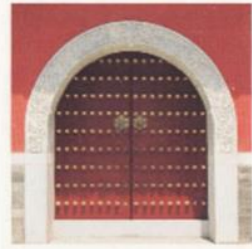

门琸
图 23 建筑上的金属部件
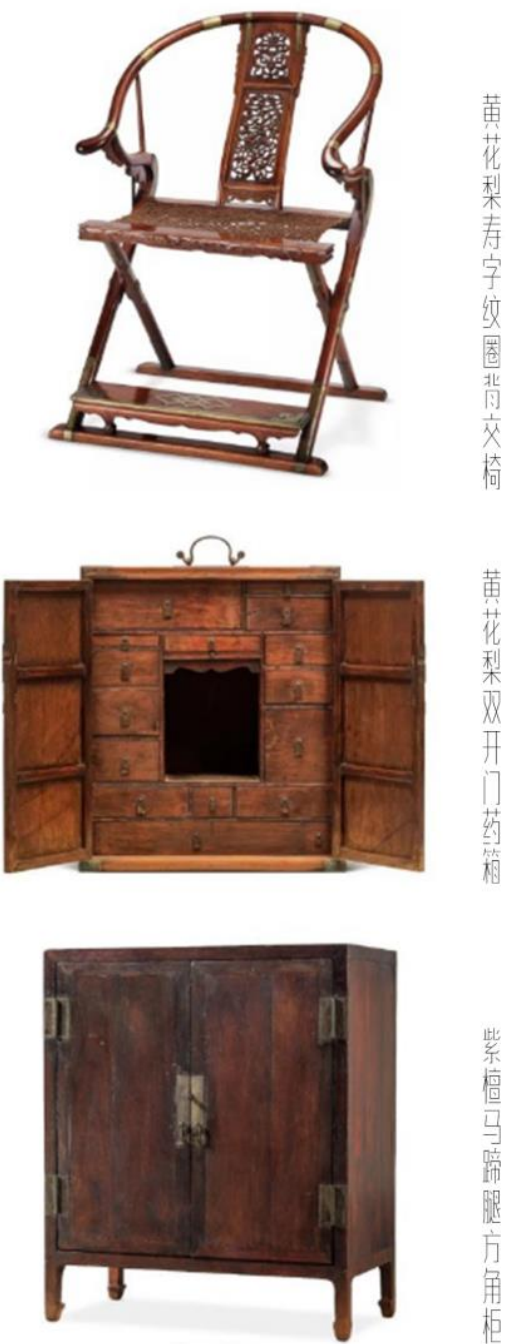

图 24 家具中的金属部件

\section{6. 结语}

我国古代建筑与明式家具可以说是继承了源远 流长的优秀木工传统, 并经历了长期的实践与探索, 
把木作艺术提高至前所未有的水平, 传世实物就是最 好的见证。如果说传统中式建筑的精华是错综复杂的 斗拱设计, 那就不难让我们追溯到家具工艺中造诣非 凡的榫印结构。在深受社会因素制约的情况下, 相互 影响又共同发展。

本文作为明式家具文化研究的细化，以结构形制、 造型规律、材料衔接、附属构件四个方面的实例来展 示明式家具与中国古代建筑的同源性, 为呈现二者相 辅相成之关系提供具体化成果。通过实例图式, 从而 折射出明式家具的发展延续了中国传统建筑中的木 构架原理, 把庞大的斗拱结构微缩于小之数倍的家具 之上, 正所谓巧夺天工, 美轮美负。

\section{REFERENCES}

[1] Meng Meng. On the influence of Chinese ancient architecture and spatial form on Ming style furniture [j]. industrial design, 2018, 000 (012): 102-103.

[2] Chen Yaodong. Study on Luban's mirror of Chinese classics, [m]., China Architecture Industry Press, 2010.

[3] Hou Yanfang, Hu Wei soldier. Damage detection of ancient wood structures based on cross correlation function amplitude vector $[c] / /$ Chinese mechanics conference and Tsien Hsueshen's 100th anniversary birthday commemorative meeting. 2011. 